\title{
Using a Collaborative Database to Enhance Students' Knowledge Construction
}

\author{
Yigal Rosen and Rikki Rimor \\ Open University of Israel, Raanana, Israel
}

\author{
igal.rosen@gmail.com; rikkiri@openu.ac.il
}

\begin{abstract}
This study focuses on academic online course in collaborative database learning environment and examines the conditions for effectiveness of collective and individual knowledge construction in this environment. The purpose of this study was to examine whether learners with a collaborative learning orientation differ from learners with an individual learning orientation, as was measured through their contribution to the process of knowledge construction in a collaborative online database environment. The results of the study showed differential achievements among learners with different learning orientations. The learners with collaborative learning orientation succeeded more in the collective criteria of knowledge construction compared to the less collaborative ones. On the other hand, the less collaborative participants within the forum gained higher scores in the personal criteria of knowledge construction compared to the collaborative ones. While the 'collaborative learners' contributed more collective knowledge, the 'individual learners' focused on constructing their own personal knowledge. These findings have important implications on planning, coordinating and evaluating collaborative learning environment.
\end{abstract}

Keywords: Collaborative learning, learning orientation, online database, argumentation, knowledge tool.

\section{Introduction}

The most important challenges in designing e-learning environments are to ensure effective knowledge construction and to develop thinking skills involving personal and collaborative learning processes (e.g., Koohang, 2009; Rimor, \& Rosen, in press; Rosen, 2009). Yet, there is a lack of empirical evidence relating to the interaction of individual and collaborative knowledge constructing processes in e-learning environments. The relationship between the individual and the group components in the process of collaborate knowledge building deserves further elaboration and research in various e-learning environments, as well as the examination of different learning orientations. The purpose of this study was to examine whether learners with a collaborative

Material published as part of this publication, either on-line or in print, is copyrighted by the Informing Science Institute. Permission to make digital or paper copy of part or all of these works for personal or classroom use is granted without fee provided that the copies are not made or distributed for profit or commercial advantage AND that copies 1) bear this notice in full and 2) give the full citation on the first page. It is permissible to abstract these works so long as credit is given. To copy in all other cases or to republish or to post on a server or to redistribute to lists requires specific permission and payment of a fee. Contact Publisher@InformingScience.org to request redistribution permission. learning orientation differ from learners with an individual learning orientation, as was measured through their contribution to the process of knowledge construction in a collaborative online database environment. The study examined students' contribution to the database through personal and collective criteria of knowledge construction. Students' collaborative learning orientation was measured by their previous contribution

\section{Editor: Alex Koohang}

An earlier, shorter version of this paper was presented at the Chais conference 2009, in Raanana, Israel, and included in Y. Eshet-Alkalai, A. Caspi, S. Eden, N. Geri, \& Y. Yair (Eds.), Proceedings of the Chais conference on instructional technologies research 2009: Learning in the technological era. Raanana: The Open University of Israel. http://www.openu.ac.il/research center eng/conferences.html 
to the forum of the e-learning course. This paper presents the rationale for collaborative knowledge construction in online learning environments and discusses the results of the study regarding collaborate knowledge building. Measures of individual and collective knowledge are presented. The relationship between these measures and their contribution to e-learning environments are further discussed and challenged.

\section{Theoretical Background}

The theoretical framework of our study is based on the Social Constructivist approach, as well as on the cognitive approach of knowledge construction and its application in database learning environment (e.g. Berieter, \& Scardamalia 1989; Bruner, 1973; Glazer, 1984; Jonassen, 1999; Papert 1980, 1993; Perkins, 1986; Piaget, 1954; Salomon, 2002; Vygotzky, 1978). Research on educational applications of databases claim that students should have access to different data resources as well as the ability to use this data in order to construct new knowledge. The difference between accessing information and constructing new knowledge is an important issue for investigation (Rimor, 2002; Salomon, 2002). In the current study we focus on construction of knowledge through collaborate learning in online databases.

Databases are perceived as "cognitive tools", as they assist learners in the cognitive process of knowledge construction (Jonassen, 1999). These tools involve the learner in a range of knowledge areas and they include, for example, databases, concept maps, micro-worlds, expert systems, wiki, as well as virtual reality environments. Computer-based cognitive tools have been developed with the aim of acting as "intellectual partners" (Perkins, 1993) which reinforce the learner's ability to design and plan the representations of his/her knowledge. Construction of a database was chosen in the study as a learning activity representing this concept. Learning in a database environment requires the learner to be active by defining groups of data, classifying them in a database, and presenting arguments for justifying the classification (Jonassen, 1999; Nason, Lloyd, \& Ginns, 1996; Rimor, 2002).

The socio-cultural view of development, as described by Vygotsky (1978), claims that learning is situated within the learner's zone of proximal development, where the learner increases his/her performance with the support of an agent in his/her learning environment who can assist the individual to optimize his/her learning potential. Therefore, learning best occurs when students are taught within their zone of proximal development as the gap between their potential and performance has been decreased (Vygotsky, 1978). Based on Vygotsky's theory, researchers propose small group work with sufficient scaffolding and appropriate task instructions. In these learning environments the participants are most likely to be situated within their zone of proximal development, which in turn facilitates their understanding and learning (Ormrod, 2005).

Self-reflectivity is one of the most important components in collaborative knowledge building (Singh, Hawkins, \& Whymark, 2007; Yukawa, 2006). Collaborative reflective social discourse facilitates visibility of different perspectives of the learners. The emphasis in collaborative knowledge building is on developing shared objects and collaborative advancement of conceptual artifacts. This process includes a cycle of personal understanding that focuses on the individual level. Once the learner has presented his personal perspective on the issue, the group engages in discussion to develop shared knowledge. In challenging situations, an individual uses reflective thinking to interact with conceptual artifacts, discuss the issues with peers, and develop a shared understanding. The collaborative work-place represents a common space through which the learners are interacting.

Databases can be seen as a knowledge medium - a combination of knowledge types, representation formats, and purpose of represented knowledge (Sowa, 2000). Building a database involves procedural knowledge including strategies for building the database, and meta-cognitive knowl- 
edge including insights on the knowledge base of the data, and on the structure of the database itself (Rimor, 2002). For these reasons, we consider the database as a cognitive tool enabling the process of construction of knowledge.

Constructing a collaborative database suggests activities that facilitate knowledge construction to learners (Rimor, 2001). They are mutually involved in establishing and sharing their conceptions and can approach a problem from multiple perspectives in a common space (Weinberger, 2003). The analysis of knowledge as co-constructed by the group as well as acquired by the individual has been suggested through interaction with various interfaces (Means \& Voss, 1996; Singh et al., 2007; Weinberger 2003, Weinberger, \& Fischer, 2006). It is assumed that a specific interface design may substitute extensive training and feedback by co-present moderators and, hence, provides a standardized quality of collaborative knowledge construction.

The beneficial effects of shared representations are highly dependent on the degree of prior knowledge of all communicants (Fischer, 1998; O'Donnell, \& Dansereau, 2000). Cooperation scripts, which are induced by educational facilitators, have generally shown to be a promising approach to foster collaborative knowledge construction. Bereiter (2002) defines conceptual artefacts as products of objects of thinking and reasoning that can be collectively argued about. The concept of collaborative knowledge building refers to collective work for the advancement and elaboration of conceptual artifacts. It is conceptualized as a social process in which participants co-construct knowledge through social interactions (Lipponen, 2002; Stahl, 2000). An Integrated Model of Collaborative Knowledge Building suggests that each participant engaged in the activity uses reflective thinking as a tool to develop or interpret the meaning of conceptual artefacts and, hence, co-creates knowledge with the help of mediating artefacts. The model explains collaboration in practice, based on activity theory and the role of reflection (Singh et al., 2007).

Working in a collaborative environment involves processes of reflection and argumentation. Argumentation refers to making convincing claims backed up by sound evidence and broad understanding of various aspects of an issue (e.g. Coirier, Andriessen, \& Lucille, 1999; Jeong, 2004; Kuhn, 1991; Nussbaum, 2005; Spatariu, Hartley, Schraw, Bendixen, \& Quin, 2007). Argumentative learning activities can serve as an effective mechanism of diffusion of knowledge through a network of exchanges in small groups (Roth, \& Bowen, 1995). From a Vygostkian point of view argumentative activity overtly bridges between interpersonal and intrapersonal processes (Vygotsky, 1978, 1934/1986).

The relationship between the individual and the group components in the process of collaborate knowledge building deserves further elaboration and investigation in various learning environments. The question chosen for examination in this study is whether learners with a collaborative learning orientation differ from learners with an individual learning orientation, as was measured through their contribution to the process of knowledge construction in a collaborative online database environment. The study was designed to expand the knowledge about the collaborative learning processes and possible individual and collective achievements, based on prior characterization of learners.

\section{Method}

Fifty eight M.A. students participated in an online course that referred to knowledge construction processes in technological based environments. Most of the students participated in at least one online course in the past. The students were required to take part in the forum of the course and in an online collaborative assignment based on constructing a shared database on the Internet. (One of three assignments during the course). The purpose of the assignment was to construct a database representing various types of knowledge. The construction of the database included students' selection of statements from the course forum, classifying them according to four types of knowl- 
edge: declarative, procedural, structural, metacognitive. The work was carried out online in a collaborative "Google Docs" database (Google Spreadsheets). The construction of a Google database enables cognitive activities of organizing, classifying, and representing data in a collaborative environment. This process of database construction was initiated by the students' sorting individually their statements in the forum and re-locating them in the proper fields of the database, relating to the various types of knowledge. This activity was accompanied by individual argumentation and mutual feedback among the participants. At the end of the process the students made a final group decision on the classification of the statements. All the classifications and explanations were documented in the database. The participants shared a common purpose, a prior knowledge of the types of knowledge, a common virtual space for classifying their statements, and a common space for presenting arguments, reasoning and question during the process of constructing the database. The purpose was to build a collaborative agreement in the team in regard to the sorting of the forum's statements in the database. The learning activities were conducted in teams of 3-4 students, over the course of six weeks, and assessed by two main dimensions: (a) the student's process of individual knowledge construction and (b) the team's process of collaborative knowledge construction. Each participant was examined according to his/her individual contribution to the database and according to the extent of his/her previous activity in the shared forum.

Participants were classified into "active" and "less active" based on the extent of prior activity in the course forum. Rate of activity in the forum was measured operationally according to three quantitative criteria: (1) The scope of the student's participation in the discussions (how many times did he/she participate?); (2) How many queries were initiated by the student in the forum? and (3) How many proposed additional information and links contributed to the forum? A student with an average rate and above classified as "active", otherwise the student classified as "less active". Individual knowledge in the online database was measured operationally according to the student's individual success in correctly classifying the forum's statements according to the four types of knowledge mentioned above. Classification was based on terminology and articles that were studied during the course. Collective knowledge in this environment was measured operationally by the index of accuracy of the group assignment, which verifies the individual classifications of various types of knowledge. Completion of this assignment was a result of the teams' discussion and argumentation process to gain an agreement among the participants. Regarding the raw test scores, the errors were distributed across all four types of knowledge classification (declarative, procedural, structural, and metacognitive). If the decision of the group was to change the classification of one of the members, they were allowed to change it only at the collective level. The initial classifications of the group members, as well as the group decisions, were documented in the database. Instructor's feedback accompanied the process as well, prompting the participants to accomplish their task.

\section{Results}

Figure 1 presents the grades of the participants in the indices of individual knowledge and group knowledge, as was obtained as a result of constructing the database. The participants were classified as "active" or "less active" on the basis of the extent to which they independently initiated queries for group discussion within the framework of the course forum, as outlined in method section. 


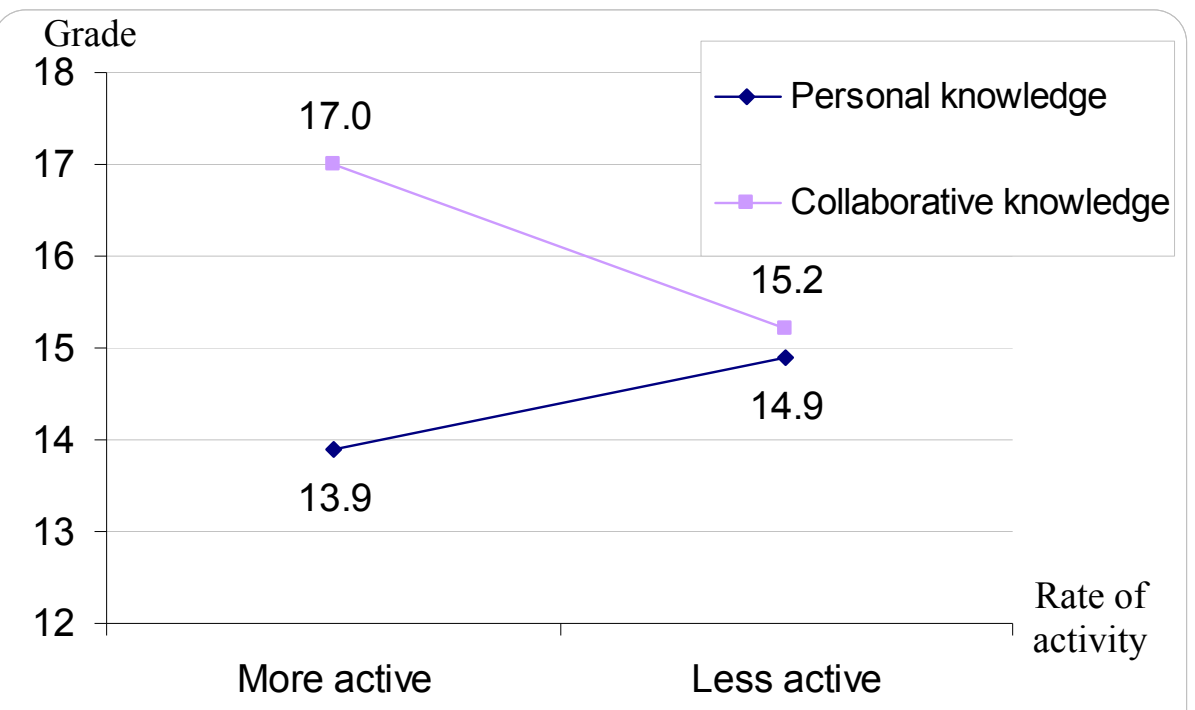

Figure 1: Grades of "More active" and "less active" participants in the forum by indices of "personal knowledge" and "collaborative knowledge" in construction of online database (more active: $\mathrm{N}=34$, less active: $\mathrm{N}=24$ )

The findings indicate that the active participants were more successful in the group index of knowledge construction, compared to the less active participants (average grade of 17.0 versus $15.2 ; \mathrm{t}=5.1, \mathrm{p}<0.1)$. Accordingly, the study found a tendency that the less active participants in the course forum had much more success in the personal index of knowledge construction, compared to more active participants (average grade of 14.9 versus $13.9 ; \mathrm{t}=2.1, \mathrm{p}<0.5$ ). The findings demonstrate the differential nature of the process of knowledge construction and the differential type of achievements among learners with a different learning orientation, as shown in Figure 1.

\section{Discussion}

Social-constructivists emphasize social interactions as a precondition for learning and knowledge building. Consequently, there has been a prevailing focus on encouraging team work at various learning environments. Our findings elicit the need to re-consider individual-oriented learners whose knowledge expertise exceeds their level of contribution to the group.

In social constructivism, knowledge is developed through cognitive activity that occurs during the discussion and debate with other people. The social interaction serves as a scaffold for the cognitive activity, to occur. "Learners should be provided with the tools, resources, and support necessary to manage their own learning and assigned tasks" (Vrasidas, 2000, p. 9).

In our research, students were able to develop their own knowledge as they collaborated to construct a common database online. They were supported by previous knowledge (course readings), mutual feedback, and written dialogues with team members and by reflecting overtly on their own actions and considerations in regard to the content of the database. Previous studies of online group action learning provided evidence of the potential of collaborative reflection as a core process in group learning, enabling students to construct their own knowledge through metacognitive processes (Reingold, \& Rimor, 2008; Yukawa 2006).

Our findings indicate that the more active participants were more successful in 'collective knowledge' construction, compared to the less active participants. 
On the other hand it was found that the less active participants in the course forum had much more success in the personal index of knowledge construction, compared to more active participants. While the 'collaborative learners' contributed more collective knowledge, the 'individual learners' focused on constructing their own personal knowledge.

The methodology of the current research enabled us to distinguish between individual's performance (individual knowledge) and collective contribution of the group (collective knowledge) in the construction of the online database. In addition, we defined an index to measure orientation towards collaborate learning. Operational analysis of previous activity in the forums elicited the extent to which participants are practically oriented towards collaborate learning. The results show that the "less oriented" students exceeded the "more oriented" ones in the parameters of individual knowledge. It means that students who were less active in the forum managed to construct their own knowledge significantly more than the active ones.

These findings challenge the theoretical claims of the social constructivist approach to learning. It empirically reveals those learners who tend to collaborate less, yet they still succeed in constructing their own knowledge.

However, the different characteristics of the two learning environments involved in this research should be considered closely. It seems likely that one can be less active in the forums' discussions, yet fulfill his cognitive potential in the environment of the database. This was achieved through the individual contribution to the construction of the database, as well as one's succeeding in arguing and debating theoretical considerations to verify his/her performance. Hence, the contribution of argumentation to the process of knowledge construction has to be further investigated.

\section{Conclusions}

The findings signify the differential achievements among learners with different learning orientation. While learners with a collaborative learning orientation tend to contribute to the increasing group knowledge, learners with an individual learning orientation are focused on personal knowledge construction.

There are two main conclusions to the study's findings obtained in the environment of an online collaborative database:

1. Learners with a collaborative learning orientation are different in their personal and group achievements, compared to learners who tend to individual learning.

2. The study's findings emphasize the importance of creating a balance in groups of learners in online collaborative environments according to their initial orientation to group learning.

The educational implications of the study are in the importance of the balance of the learners groups in online collaborative environments according to their initial orientation to group learning. To obtain a high extent of effectiveness of the learning process, there is a need for the characterization of learners according to their tendency for group and individual work and to balance the groups in accordance with these features.

In sum, we recommend further investigation of the process of collaborative knowledge building in e-learning environments. The relationship between the individual and the group components in the process of collaborative knowledge building deserves further elaboration and investigation in various learning environments. Different learning orientations of the participants towards collaborative learning on one hand, and the use of argumentation as a mechanism of knowledge construction on the other hand, may contribute to the results of further comprehensive studies. 


\section{References}

Bereiter, C. (2002). Education and mind in the knowledge age. Mahwah: NJ: Lawrence Erlbaum Associates.

Bereiter, C., \& Scardamalia, M. (1989). Intentional learning as a goal of instruction. In L. B. Resnick (Ed.), Knowing, learning and instruction: Essays in honor of Robert Glazer. Hillsdale NJ: Lawrence Erlbaum Associates.

Bruner, J. (1973). Beyond the information given: Studies in the psychology of knowing. New York: Norton.

Coirier, P., Andriessen, J., \&Lucille, C. (1999). From planning to translating the specificity of argumentative writing. In J. Andriessen \& P. Coirier (Eds.), Foundations of argumentative text processing (pp. 128). Amsterdam: Amsterdam University Press.

Fischer, F. (1998). Mapping procedures as cognitive tools for problem-oriented learning. Frankfurt: Lang.

Glazer, R. (1984). Education and thinking - The role of knowledge. American Psychologist, 45(2), 29-39.

Jeong, A. (2004). The combined effects of response time and message content on growth patterns of discussion threads in computer-supported collaborative argumentation. Journal of Distance Education, 19(1), 36-53.

Jonassen, D. H. (1999). Computers in the classroom: Mindtools for critical thinking. Englewood Cliffs, NJ: Prentice Hall.

Koohang, A. (2009). A learner-centered model for blended learning design. International Journal of Innovation and Learning, 6(1), 76-91.

Kuhn, D. (1991). The skills of argument. New York: Cambridge University Press.

Lipponen, L. (2000). Towards knowledge building discourse: From facts to explanations in primary students' computer mediated discourse. Learning Environments Research, 3, 179-199.

Means, M. L., \& Voss, J. F. (1996). Who reasons well? Two studies of informal reasoning among children of different grade, ability and knowledge levels. Cognition and Instruction, 14, 139-178.

Nason, R., Lloyd, P., \& Ginns, I. (1996). Format-free database and the construction of knowledge in primary school science projects. Research in Science Education, 26(3), 353-373.

Nussbaum, E. M. (2005). The effect of goal instructions and need for cognition on interactive argumentation. Contemporary Educational Psychology, 30(3), 286-313.

Ormrod, J. E. (2005). Educational psychology (5th ed.). New Jersey: Prentice Hall.

O'Donnell, A. M., \& Dansereau, D. F. (2000). Interaction effects of prior knowledge and material format on cooperative teaching. Journal of Experimental Education, 68, 101-118.

Papert, S. (1980). Mindstorms: Children, computers, and powerful ideas. New York: Basic Books.

Papert, S. (1993). The children's machine. Rethinking school in the age of the computer. New York: Basic Books.

Perkins, D. N. (1986). Knowledge as design. Hillsdale, NJ: Lawrence Erlbaum Associates.

Perkins, D. N. (1993). Person-plus: A distributed view of thinking and learning. In G. Salomon (Ed.), Distributed cognition: Psychological and educational considerations (pp.88-110). NY: Cambridge University Press.

Piaget, J. (1954). The construction of reality in the child. New York: Basic Books.

Reingold, R., \& Rimor, R. (2008). Instructor's scaffolding in support of student's metacognition through a teacher education online course - A case study. Journal of Online Interactive Learning, 7(2), 139-151.

Rimor, R. (2001). Database as a cognitive tool. Educational Researcher, 20(3), 2-9. 
Rimor, R. (2002). From search for information to construction of knowledge: Organization and construction of knowledge in database environment. Doctoral Dissertation, Ben-Gurion University of the Negev, Israel [In Hebrew].

Rimor, R., \& Rosen, Y. (in press). Collaborative knowledge construction: Why to promote and how to investigate. In S. Mukerji \& P. Tripathi (Eds.), Cases on technological adaptibility and transnational learning: Issues and challenges. IGI Global.

Rosen, Y. (2009). The effects of an animation-based on-line learning environment on transfer of knowledge and on motivation for science and technology learning. Journal of Educational Computing Research, 40(4), 439-455.

Roth, W. M., \& Bowen, G. M. (1995). Knowing and interacting: A study of culture, practices, and resources in a Grade 8 open-inquiry science classroom guided by a cognitive apprenticeship metaphor. Cognition and Instruction, 13(1), 73-128.

Salomon, G. (2002). Technology and pedagogy: Why don't we see the promised revolution? Educational Technology, 42(2), 71-75.

Singh, G., Hawkins, L., \& Whymark, G. (2007). An integral model of collaborative knowledge building. Interdisciplinary Journal of Knowledge and Learning Objects, 3, 85-104. Retrieved from http://ijello.org/Volume3/IJKLOv3p085-105Singh385.pdf

Sowa, J. F. (2000). Knowledge representation: Logical, philosophical, and computational foundations. Pacific Grove, CA, USA: Brooks/Cole.

Spatariu, A., Hartley, K., Schraw, G., Bendixen, L. D., \& Quin, L. F. (2007). The influence of the discussion leader procedure on the quality of arguments in online discussions. Journal of Educational Computing Research, 37(1), 83-103.

Stahl, G. (2000). A model of collaborative knowledge-building. Paper presented at the Proceedings of Fourth International Conference of the Learning Sciences (ICLS 2000), Ann Arbor, MI.

Vrasidas, C. (2000). Constructivism versus objectivism: Implications for interaction, course design, and evaluation in distance education. International Journal of Educational Telecommunications, 6(4), 339362 .

Vygotsky, L. S. (1978). Mind and society: The development of higher mental processes. Cambridge, MA: Harvard University Press.

Vygotsky, L. S., (1986). Thought and language. Cambridge, MA, MIT Press. (Original work published 1934)

Weinberger, A. (2003). Scripts for computer-supported collaborative learning effects of social and epistemic cooperation scripts on collaborative knowledge construction. Dissertation an der Fakultät für Psychologie und Pädagogik der Ludwig-Maximilians-Universität München.

Weinberger, A., \& Fischer, F. (2006). A framework to analyze argumentative knowledge construction in computer-supported collaborative learning. Computers and Education, 46(1), 71-95.

Yukawa, J. (2006). Co-reflection in online learning: Collaborative critical thinking as narrative. International Journal of Computer-Supported Collaborative Learning, 1(2), 203-228. 


\section{Biographies}

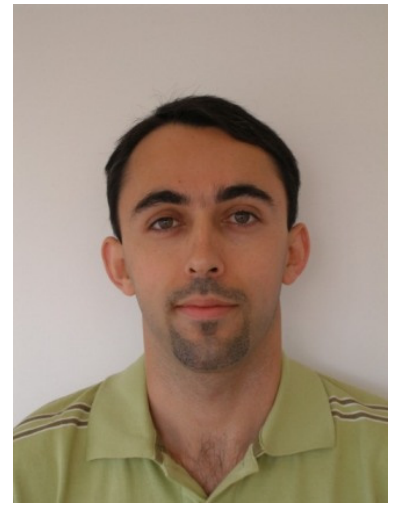

Dr. Yigal Rosen's research interests focus on developing higher-order thinking skills and inter-group social skills in novel learning environments. He obtained his $\mathrm{PhD}$ degree from the Faculty of Education at the University of Haifa in 2006. Dr. Rosen was a post-doctoral fellow at School of Education at Tel Aviv University (2006-2007), and a postdoctoral fellow at the Graduate School of Education at Harvard University (2007-2008). He is a faculty member at The Open University of Israel, Department of Education and Psychology and at the University of Haifa, Faculty of Education. His most recent publication is: Rosen, Y. (in press), Effects of animation learning environment on knowledge transfer and motivation to learn science and technology, Journal of Educational Computing Research, 40(4).

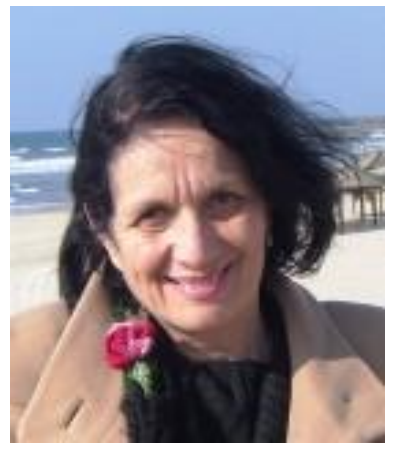

Dr. Rikki Rimor is a faculty member and course designer at The Open University of Israel, Department of Education and Psychology, Graduate program of Learning Technologies. Dr. Rimor is an academic consultant of The Unit for Advancement of Learning and Teaching. She was a head of Center for Pedagogy \& Innovative Technologies at Teachers College of Technology, Tel-Aviv (2005-2007). Dr. Rimor participated in TAP program of the Harvard Graduate School of Education. She obtained her PhD degree from the Department of Education at the Ben-Gurion University of the Negev in 2002. Her most recent publication is: Rimor, R., Reingold, R., \& Heiman, T. (2008), Instructor's scaffolding in support of student's metacognition through an online course: Why to promote and how to investigate. In: Zumbach, J., Schwartz, N., Seufert,. \& Kester, L. (Eds.). Beyond Knowledge: the Legacy of Competence. Meaningful computer-based Learning environments (pp.43-53). Springer. 